\title{
El funcionamiento de los signos y de las semióticas en el capitalismo contemporáne ${ }^{1}$
}

\section{Mauricio Lazzarato²}

Con el posfordismo aparece una nueva distribución de las semióticas, una nueva división de lo sensible que atañe a los saberes y los signos. A pesar de que en las décadas de 1960 y 1970 la lingüística fue el paradigma de las ciencias sociales, son pocos los autores que han analizado esta configuración. Tomamos de Deleuze y Guattari la distinción entre semióticas asignificantes y semióticas significantes, para referirnos a las diferentes funciones de signos, discursos y saberes que vimos operando en este conflicto.

En las sociedades contemporáneas, los signos y las semióticas funcionan siempre bajo un doble registro. El primero es el de la "representación" y el "significado", organizado mediante semióticas significantes (la lengua) con vistas a la producción del "sujeto", del "individuo", del "yo" [“je”]. El segundo es el registro maquínico, organizado mediante semióticas asignificantes (tales como los signos monetarios o bursátiles, los lenguajes informáticos que hacen que las máquinas funcionen, o numéricos de producción de imágenes, sonidos e información, las ecuaciones, las funciones, los diagramas de la ciencia, la música, etc.) "capaces de poner en juego signos que tienen por otra parte un efecto simbólico o significante, pero cuyo propio funcionamiento no es ni simbólico ni significante”.

Este segundo registro no busca la constitución del sujeto, sino la captura y activación de los elementos presubjetivos y preindividuales (afectos,

\footnotetext{
1 Este texto ha sido publicado por primera vez en: VV.AA. (2007). Producta50, Generalitat de Catalunya - Department de Cultura i Mitjans de Comunicació, Barcelona. Y se incluye en este número con autorización explícita de la casa editorial bajo la licencia Creative Commons.

2 Maurizio Lazzarato es filósofo, escritor, colaborador habitual de la revista Futur Antérieur y miembro del consejo editorial de la revista Multitudes.
} 
emociones, percepciones), y transindividuales, para hacerlos funcionar como piezas, como engranajes de la máquina semiótica del capital.

\section{Las funciones de sometimiento social y de alie- nación subjetiva de las semióticas significantes}

El sistema capitalista, a través de la representación y el significado, produce y distribuye roles y funciones, nos dota de una subjetividad y nos asigna una individuación (identidad, sexo, profesión, nacionalidad, etc.) de manera que todo el mundo queda atrapado en una trampa semiótica significan-te y representativa.

Esta operación de "sometimiento social" a identidades y roles establecidos, pasa por la subordinación de la multiplicidad y la heterogeneidad de las semióticas presignificantes o simbólicas al lenguaje y sus funciones de representación y significado.

Las semióticas simbólicas corporales (todo medio de expresión preverbal, corporal, icónico - la danza, la mímica, la música, una somatización, una crisis nerviosa, un ataque de llanto, intensidades, movimientos, ritmos, etc.-) no dependen ni del lenguaje significante ni de la conciencia. No ponen en juego un hablante y un oyente perfectamente discernibles, como ocurre en el modelo comunicacional y en el lingüístico; y la palabra no ocupa un primer plano. Estas semióticas son avivadas por los afectos, y dan lugar a relaciones difícilmente asignables a un sujeto, a un yo [moi], a un individuo. Desbordan los límites subjetivos individualizantes (de las personas, las identidades, los roles y funciones sociales) dentro de los cuales el lenguaje querría encerrarlos y reducirlos. El "mensaje" no pasa por cadenas lingüísticas sino por el cuerpo, posturas, ruidos, imágenes, mímicas, intensidades, movimientos, ritmos, etc.

El empleo de semióticas significantes tiene, según Guattari, las siguientes consecuencias: "La subjetividad pática [afectiva] que está en la raíz de todos los modos de subjetivación, queda ocultada (...) y tiende a ser sistemáticamente evacuada de las relaciones de discursividad, a pesar de que los operadores de discursividad están esencialmente cimentados en ella” (Guattari, 1992). 
El hecho de plegar estas modalidades de expresión a las semióticas significantes es una operación política, ya que, por una parte, la "toma de significado es siempre inseparable de una toma de poder” (Guattari, 1980) y, por otra, no hay significación ni representación independientemente de significados y representaciones dominantes.

La potencia de actuar de los signos lingüísticos y no lingüísticos se pliega a la lógica de la representación y significado, que neutralizan y reprimen todas las demás funciones del lenguaje y de los signos.

Hay una pretensión común a la lógica capitalista de las sociedades disciplinarias y a la lógica socialista y comunista: la relación con lo real debe pasar forzosamente por una mediación. Sin significado y sin representación, no hay acceso a lo real. En la tradición del movimiento obrero, no hay política posible sin "toma de conciencia" (significado) y sin "representación" del pueblo o la clase por el "partido".

Semiótica y política, gobierno de los signos y gobierno del espacio político están estrechamente ligados.

\section{Las funciones de servidumbre ${ }^{3}$ maquínica de las semióticas asignificantes}

El concepto de sometimiento social de Guattari coincide en muchos puntos con el concepto de "gobierno por medio de la individualización" que, según Foucault, caracteriza las sociedades disciplinarias. Las funciones de "servidumbre maquínica", por el contrario, no encuentran ninguna correspondencia ni en las teorías políticas ni en las lingüísticas, siendo este concepto una de las contribuciones fundamentales de Deleuze y Guattari para la comprensión de las sociedades contemporáneas.

3 «Asservissement» (en le texto original), tiene un doble sentido. a) Servidumbre: la condición de siervo o de esclavo, el acto de subyugar (esclavitud, sujeción, sumisión) como sistema de dependencia que liga el siervo al feudo. El siervo es un individuo que no tiene derechos, que no dispone de su persona, ni de bienes, cuyos servicios están adscritos a la gleba, y como ésta, son transferibles. b) El sentido cibernético de mecanismo de servidumbre: sistemas de control automático, con retroalimentación (feed-back) aplicados profusamente a la industria mecánica, como multiplicadores de energía y cuya especialidad es el control de los procesos. En este contexto, las personas son consideradas como dispositivos que procesan (transforman) información para una acción conforme a las necesidades de un sistema dado. Desde este punto de vista, las acciones humanas no se limitan a ser pensadas como adecuadas o no, en cuanto funciones de un sistema global (Guattari, 2004). 
El registro maquínico de la producción semiótica del capital funciona sobre la base de semióticas asignificantes, de los signos que, en vez de producir un significado, provocan una acción, una reacción, un comportamiento, una actitud, una postura. Estas semióticas no significan, pero ponen en movimiento, activan.

Para aclarar la función de servidumbre maquínica, utilizaremos la descripción que Brian Massumi ha hecho de la misma. En un bello artículo, nos explica que después del 11 de septiembre de 2001, la televisión se ha convertido en el "canal privilegiado de la modulación afectiva, en tiempo real, en momentos socialmente críticos” (Massumi, 2005, pp. 31-48), es decir, que después de los atentados de Nueva York y Washington, se ha convertido en el canal privilegiado de la servidumbre maquínica.

La oficina de seguridad interna estadounidense estableció un sistema de alerta cifrado por colores (del verde al rojo) para calibrar la ansiedad del público ante la amenaza "terrorista". Este sistema de alerta no va dirigido a la cognición y la conciencia de los sujetos, sino "más bien a la irritabilidad de los cuerpos”, es decir a los componentes preverbales y preindividuales de la subjetividad. Las señales perceptivas se utilizan para activar directamente la sensibilidad antes que para "reproducir una forma" o "transmitir un contenido definido". Las alertas son "señales sin significado" que en sí mismas no llevan ningún sentido ideológico, ningún discurso, pero que activan una respuesta "refleja (a saber, no reflexiva) de los cuerpos".

El término define aquí una servidumbre mecánica. Los mecanismos de servidumbre son normalmente diagramas de bloques que revelan la dependencia funcional entre los elementos y un sistema de control.

Esta respuesta a "signos perceptivos que el sistema tiene por objeto generar conecta, sin hilos, al gobierno con el sistema nervioso de cada individuo" (Massumi, 2005, pp. 31-48).

El objeto de gobierno es aún, como en Foucault, la población, pero aquí "la población entera ha devenido nerviosidad en red", una inmensa "red neuronal" que reacciona de manera refleja a los estímulos que le son dirigidos (Massumi, 2005, pp. 31-48). 
Según Massumi, no se trata de la transmisión de un mensaje, de un intercambio de información de contenido ideológico, sino de una intervención que actúa "allí donde surge la experiencia”. Este sistema actúa sobre las condiciones de aparición de la emoción, de la palabra, de la acción. Afecta a la subjetividad en su proceso de constitución mismo, dentro de modalidades de su propia producción.

"Se trata menos de una comunicación que de una germinación asistida de potenciales para la acción, cuyo resultado no puede determinarse con precisión de antemano, pero cuya determinación variable puede programarse en colores" (Massumi, 2005, pp. 31-48).

Este sistema pierde en capacidad de determinación, ya que no puede controlar los efectos y las reacciones de los individuos, pero gana en posibilidad de formateado del desarrollo de la subjetividad.

Los signos monetarios y bursátiles, la televisión, la ciencia, la música, etc, pueden funcionar como máquinas de producción de signos que escriben directamente sobre lo real y sobre el cuerpo, sin pasar por un significado o una representación.

La circulación del miedo, de la angustia o del pánico que constituye la atmósfera y la tonalidad en las que están inmersas nuestras sociedades "de la seguridad pública", se activa por medio de máquinas de signos que no van dirigidos a la conciencia, sino directamente al sistema nervioso, a los afectos, a las emociones.

En lugar de estar centradas en la lengua, las semióticas simbólicas del cuerpo son actividad como tal por la producción industrial, maquínica, no humana de imágenes, sonidos, palabras, intensidades, movimientos, ritmos, etc.

Si las semióticas significantes tienen una función de alienación subjetiva, de "sometimiento social", las semióticas asignificantes tienen una función de "servidumbre maquínica”. Las semióticas significantes operan una 
sincronización y una modulación de los componentes preindividuales y preverbales de la subjetividad, haciendo que los afectos, las percepciones, las emociones, etc. funcionen como piezas, componentes, elementos de una máquina (servidumbre maquínica). Podemos funcionar exactamente igual a componentes de input/output de máquinas semióticas, como simples relés de televisión o enlaces de Internet, que permiten y/o impiden el paso de la información, de la comunicación, de los afectos.

A diferencia de las semióticas significantes, las semióticas asignificantes no conocen ni personas, ni roles ni sujetos. Mientras que el sometimiento involucra personas globales, representaciones subjetivas molares fácilmente manipulables, "la servidumbre maquínica agencia elementos infrapersonales, infrasociales, en razón a una economía molecular del deseo”.

La potencia de estas semióticas reside en el hecho de que pasan a través de los sistemas de representación y significado en los cuales "los sujetos individuados se reconocen y alienan" (Guattari, 1980).

La servidumbre maquínica no es pues la misma cosa que la servidumbre social. Si esta última va dirigida a la dimensión molar, individuada de la subjetividad, la primera activa su dimensión molecular, preindividual, transindividual.

En el primer caso, el sistema habla y hace hablar. Reduce la multiplicidad de las semióticas presignificantes y simbólicas y la indexa al lenguaje y las cadenas lingüísticas, favoreciendo de este modo sus funciones representativas. Mientras que, en el segundo caso, no hace discursos, no habla, funciona, pone en movimiento, conectándose directamente al "sistema nervioso, al cerebro, a la memoria, etc.", activando relaciones afectivas, transitivistas, transindividuales difícilmente atribuibles a un sujeto, a un yo [moi].

Estos dos registros semióticos trabajan juntos en la producción y el control de la subjetividad, a la vez en su dimensión molar y molecular.

Como vamos a ver, los mismos dispositivos semióticos pueden ser a la vez tanto dispositivos de servidumbre maquínica como de sometimiento social 
(la televisión, por ejemplo, puede constituirnos como sujetos, usuarios, o bien utilizarnos como simples relés que hacen pasar una información, una noticia, o signos que provocan una acción-reacción). Tenemos el privilegio de estar sometidos por igual a los efectos de unos y otros.

Es preciso insistir en el sentido y el papel que juegan las semióticas asignificantes (la moneda, los dispositivos de producción maquínica de imágenes, de sonidos, de palabras, los signos, las ecuaciones, las fórmulas utilizadas por la ciencia, la música, etc.), ya que la mayoría de las teorías lingüísticas y políticas las ignoran, a pesar de que constituyen el pivote de las nuevas formas de gobierno capitalista. Precisamente, a partir de estas semióticas asignificantes se establece una nueva distribución entre lo discursivo y lo no discursivo.

Las teorías lingüísticas y la filosofía analítica ignoran su existencia y funcionamiento, pues suponen que la producción y circulación de signos y palabras es un asunto esencialmente humano, de "intercambio" semiótico entre personas. Tienen una concepción logocéntrica de la enunciación, cuando una parte creciente de las enunciaciones y de los signos es producida y trabajada por dispositivos maquínicos (televisión, cine, radio, Internet, etc.). Aquí la enunciación aún está territorializada y es logocéntrica, mientras que el capitalismo se caracteriza por una enunciación desterritorializada y maquinocéntrica. Los medios de comunicación de masas y las telecomunicaciones duplican las antiguas relaciones "orales y escriturarias", configurando nuevos agenciamientos de enunciación (individuales y colectivos).

Las teorías que hacen de la palabra y del lenguaje la forma más importante o la única forma de expresión política (Arendt, Rancière, Virno), parecen desconocer igualmente las semiologías asignificantes, ya que el proceso de subjetivación (Rancière) o individuación (Virno) se desarrolla en un espacio público concebido como una escena teatral, donde los sujetos políticos se constituyen en su dimensión molar y representativa imitando la actuación del artista o del orador ante un público.

La metáfora teatral me parece especialmente perjudicial para comprender el espacio político contemporáneo. 
El proceso de subjetivación o individuación queda entonces mutilado, pues las semióticas y las máquinas asignificantes rediseñan y reconfiguran por completo el espacio público y sus modalidades de expresión, afectando directa y profundamente a la "palabra política". Esta última ya no puede ser descrita por el funcionamiento de la potencia de actuar del lenguaje, tal y como se ejercía en la polis griega, como desde Hanna Arendt pretenden todas estas teorías. En el espacio público contemporáneo, la producción de la palabra se organiza "industrialmente", antes que "teatralmente”. El proceso de subjetivación o individuación no puede reducirse al "sometimiento social", ignorando por completo la "servidumbre maquínica".

Paradójicamente, con todas estas teorías políticas y lingüísticas contemporáneas que directa o indirectamente hacen referencia a la polis y/o al teatro, nos encontramos en una situación precapitalista.

\section{Las técnicas del espíritu}

El contenido de la subjetividad de la sociedad de control depende de una multitud de sistemas maquínicos. Para describir esta "entrada en máquina de la subjetividad", como antaño se decía "hacerse religioso", basta con recordar los gestos y las acciones que nosotros, hombres y mujeres del occidente desarrollado, realizamos todos los días en nuestra más sencilla cotidianidad.

Me levanto por la mañana y antes que nada enciendo la luz, activando así un dispositivo tecnológico que corresponde a la descodificación generalizada de flujo propio del capitalismo. Flujo cualquiera indiferente a todo producto, a toda actualización, pero que, compuesto de puntos-signo sin significado, penetrará en todos los demás dispositivos tecnológicos que activaré a lo largo del día, y los hará funcionar.

Mientras desayuno, escucho la radio. Las dimensiones espaciales y temporales habituales de mi mundo sonoro quedan en suspenso. Se neutralizan los esquemas sensomotrices habituales sobre los que se funda la percepción sonora.

La voz, la palabra y el sonido se desterritorializan, ya que han perdido toda relación con un cuerpo, un lugar, una situación, un territorio. La 
difusión radiofónica no restituye "la orientación, los límites y la estructura del espacio" de la enunciación, únicamente transmite "relaciones entre intensidades sonoras" (Cardinal, 2004).

La "radio capta menos los fragmentos sonoros como cualidades sensibles que remiten a un objeto que como una serie ilimitada de modos, de fuerzas pasivas y activas de afección...” (Cardinal, 2004).

"Lo sonoro comporta fuerzas elementales (intensidades, tonos, intervalos, ritmo y tiempo) que tienen un impacto más directo sobre la gente que el sentido de las palabras: éste es el fundamento del arte radiofónico", según Arnheim (Citado en: Cardinal, 2004). Pero también el fundamento de gobierno de las sociedades de control.

Antes de salir telefoneo para avisar de que llegaré media hora tarde. ¿Dónde tiene lugar la comunicación? ¿En mi casa? ¿En la de mi interlocutor? ¿En el dispositivo de telecomunicación? ¿Cuál es el contexto de esta enunciación?

En la calle saco dinero de un cajero automático donde un dispositivo eléctrico, informático y telemático que emite solamente puntos-signos sin ningún significado satisface mi demanda poniéndome a disposición de los signos monetarios que guardo en mis bolsillos. Flujo de poder adquisitivo que, como sabemos, no tiene realmente ningún poder, salvo el de entrar en una relación de intercambio con otros signos mercancía, que se anuncian ostensiblemente en el pasillo del metro que debo coger.

El cajero automático es un sistema de regulación y de control sin significado, pero que puede no obstante producirlos, ya que me recuerda sin cesar el saldo de mis signos sin poder, y modula, así, constantemente la necesidad de trabajar.

Antes de entrar en el metro compro un periódico. Su lectura me confronta con la especificidad capitalista de la escritura y con otra máquina de signos e información. 
Dejemos la palabra a Gabriel Tarde, que a finales del siglo XIX ya había subrayado la diferencia de este modo "mudo" de enunciación con relación al modelo de la polis griega.

Los oradores políticos griegos componían un discurso destinado a ser pronunciado en un "tiempo muy corto, en un espacio que jamás excedía el alcance de la voz humana” ante un restringido número de personas, "sustraído temporalmente a cualquier influencia circundante", elaborado por el orador en un "mismo estado de ánimo" (Tarde, 2003).

La labor del periódico es de un carácter muy distinto. "El periódico se dirige a un público mucho más amplio, pero disperso, compuesto de individuos que, mientras leen su artículo, quedan expuestos a distracciones de todo tipo; oyen los murmullos que llegan desde las conversaciones próximas, en su círculo o su café, de ideas contrarias a las del escritor” (Tarde, 2003).

Los lectores, como los oyentes de la radio, no ven nunca al escritor, ni sus gestos, sus posturas, como tampoco los rasgos de su rostro, y, a diferencia de la radio, tampoco oyen su voz ni su entonación. A diferencia del orador, que con un solo discurso influye en el juicio de los auditores, son necesarios varios artículos para obtener el mismo resultado, ya que "el artículo es sólo un eslabón en una cadena de artículos, que provienen en general de escritores diversos que componen la redacción del periódico”.

Este larguísimo y complejo "discurso mudo conocido como periódico" conduce nuestras democracias desde la Revolución Francesa.

La gran dificultad para un periódico consiste en formar a su público y conservarlo. No se establece un público ni se conserva con un cuerpo de ideas coherentes, con un despliegue armonioso de argumentos, como ocurre con la retórica del orador.

"El contenido del periódico se compone de innumerables materias, incoherentes, suministradas cada mañana por el acontecimiento del día o de la víspera. Es como si, en el transcurso de una arenga de Demóstenes 
contra Filipo, a cada instante se le hubieran acercado mensajeros con nuevas noticias y como si el relato o la interpretación de esta información hubiera constituido su discurso" (Tarde, 2003, p. 259).

Ya de regreso en casa veo, junto a otros ocho millones de franceses, un telediario. Formamos una inmensa red neuronal, una red de cuerpos y almas, afectos, emociones, pasiones simultáneamente sincronizados. Constituimos un inmenso sistema nervioso expuesto a las consignas del poder.

¿Quién habla en el televisor? ¿A quién se dirige?

El talking head es sólo el terminal de un agenciamiento "industrial" de producción de enunciación, cuya redacción, periodistas, reporteros independientes, intermitentes son sólo una parte (y no necesariamente la más importante de la cadena de producción). La voz del presentador es una "polifonía”, pero nada simpática. En su voz resuenan las voces de los poderes establecidos, de los anunciadores publicitarios, de los otros medios de comunicación escritos y electrónicos, y las de presidentes y directores generales, cuyo proyecto "cultural" consiste en volver preparar los cerebros para el marketing de las empresas.

En cada casa, cada uno de los ocho millones de telespectadores se encuentra él también en el centro de un agenciamiento, en la intersección de una serie de flujo. Los procedimientos para atraer la atención, la manera de organizar los programas, de presentar el material, recortan en diferentes lugares la experiencia de la lectura del periódico o de escuchar la radio. Pero aparecen nuevos elementos, vinculados a la especificidad tecnológica del dispositivo. Así entonces, delante del televisor soy la intersección “1. De una fascinación perceptiva provocada por el barrido luminoso del aparato, y que confina al hipnotismo; 2 . de una relación de captura con el contenido narrativo de la emisión, asociada a una vigilancia lateral con respecto a los acontecimientos circundantes (el agua que hierve en el fuego, el grito de un niño, el teléfono...); 3. de un mundo de fantasma que habita mi ensueño... Mi sentimiento de identidad personal se desvanece así en diferentes direcciones" (Guattari, 1992). 
Antes de ir al cine, respondo al correo electrónico que he recibido durante el día y entro en unos dispositivos de escritura y comunicación completamente diferentes, donde, para decirlo con Bakhtin, la "comprensión y la responsividad activa” neutralizada por la televisión puede ejercerse. Entro en otro espacio público.

Llego al cine justo a tiempo para la última sesión; tengo otra experiencia de la suspensión "ordinaria" del mundo. Esta vez concierne a la percepción y sus datos habituales de espacio y tiempo. Mi sistema sensomotriz desfallece, pues las imágenes y los movimientos ya no dependen ni de un objeto ni de mi cerebro, sino que son los productos automáticos de un dispositivo maquínico. El montaje perturba las conexiones entre situación, imagen y movimiento, haciéndome entrar en otro bloque de espacio-tiempo.

En las semiologías presignificantes o simbólicas, las materias y las formas de expresión son paralelas y no articuladas de forma lineal, como en la lengua. En una película hay diferentes líneas de expresión: la sonora, la visual, de la luz, del color, etc.

"No es cuestión de hablar de sintaxis o de clave, lo cual volvería homogénea la relación entre sus diferentes líneas".

La cuestión política que debe ponerse frente a los procesos de sometimiento y de servidumbre que acabamos de tratar, es la siguiente: ¿cómo sustraerse a estas relaciones de dominio y cómo desarrollar, a partir de estas mismas tecnologías, prácticas de libertad, procesos de subjetivación individuales y colectivos?

\section{Conclusiones}

Las semióticas significantes y asignificantes juegan un papel fundamental en el proceso de subjetivación. Este último es el resultado de la acción de una multiplicidad de elementos discursivos y no discursivos, lingüísticos y éticos, sociales y políticos, etc. En lugar de suponer su traducibilidad general en la unidad de las semióticas significantes, es necesario más bien reconocer su disyunción, su digresión, su diferencia esencial. Solamente 
trabajando la disyunción, la autonomía e independencia de estas componentes, podremos cartografiar sus efectos, sus funciones, sus modalidades de acción, su capacidad de producción, de transformación y de autoafirmación existencial.

Así pues, la polivocidad de las componentes de enunciación (lingüísticos y no lingüísticos) implica un proceso de subjetivación que no puede ser reducido a un simple resultado de operación significante o lógico-lingüística.

Se trata, al contrario, de cartografiar los "componentes de subjetivación y de enunciación en la heterogeneidad que le es más propia”, para poder determinar las funciones, los efectos y su eventual potencia de actuar.

\section{Referencias}

Guattari, F. (1992). Chaosmose. París: Galilée. [Trad. cast.: Caosmosis, Buenos Aires: Manantial, 1992].

Guattari, F. (1980). La Révolution Moléculaire. París: Recherches.

Guattari, F. (2004). Plan sobre el planeta. Madrid: Traficantes de sueños.

Massumi, B. (2005). “Fear (The Sprectrum Saids)”. Positions. East asia cultures critique, 13, 31-48.

Cardinal, S. (2004). "La radio, modulateur de l'audible”. Chimères, 53, p. 46.

Tarde, G. (2003). Les transformations du pouvoir. París: Le Seuil. 
